\title{
The crowbar model of method and its implications ${ }^{\&}$
}

\author{
(El modelo de método de palanca y sus implicaciones)
}

\author{
Thomas NiCKLES* \\ University of Nevada, USA
}

\begin{abstract}
There is a rough, long-term tradeoff between rate of innovation and degree of strong realism in scientific practice, a point reflected in historically changing conceptions of method as they retreat from epistemological foundationism to a highly fallibilistic, modeling perspective. The successively more liberal, innovation-stimulating methods open up to investigation deep theoretical domains at the cost, in many cases, of moving away from strong realism as a likely outcome of research. The crowbar model of method highlights this tension, expressed as the crowbar compromise and the crowbar fallacy. The tools-to-theories heuristic, described and evaluated by Gigerenzer and colleagues, can be regarded as an attempt by some scientific realists to overcome this compromise. Instead, it is an instance of it. Nonetheless, in successful applications the crowbar model implies a modest, instrumental (nonrepresentational) realism.
\end{abstract}

KEYWORDS: Scientific Epistemology, Scientific Innovation, Models, Realism, The Tools-to-Theories Heuristic, Digital Physics.

RESUMEN: Existe en la práctica cientifica un difícil equilibrio a largo plazo entre la tasa de innovación y el grado de realismo fuerte, un punto que se refleja en las concepciones históricamente cambiantes del método, que han pasado del fundacionalismo epistemológico a una perspectiva altamente falibilista centrada en los modelos. Los métodos cada vez más liberales y estimulantes de la innovación abren a la investigación profundos dominios teóricos a costa, en muchos casos, de alejarse del realismo fuerte como un resultado probable de la investigación. El modelo de método de palanca que destaca esta tensión, expresada como el compromiso de la palanca y la falacia de la palanca. La heurística de herramientas-para-teorías, descrita y evaluada por Gigerenzer y sus colegas, puede ser considerada como un intento por parte de algunos realistas cientificos de superar este compromiso. Pero en su lugar, es un ejemplo del mismo. No obstante, en aplicaciones exitosas, el modelo de palanca implica un modesto realismo instrumental (no representacional).

PALABRAS CLAVE: Epistemología cientifica, innovación cientifica, modelos, Realismo, heuristica herramientas-para-teorias, fisica digital.

\& Thanks to Thomas Sturm and other members of the Autonomous University of Barcelona for the conference and for organizing this special issue. My thanks also to the editor and two referees, and to Rob Moore and Devin Bray. A very early (and confusing!) mix of these ideas was presented at Cambridge in 1998.

* Correspondence to: Thomas Nickles. Dept. of Philosophy (0102), University of Nevada, Reno (Reno, NV 89557) - nickles@unr.edu - http:// orcid.org/0000-0003-1094-9976

How to cite: Nickles, Thomas. (2019). "The crowbar model of method and its implications»; Theoria. An International Journal for Theory, History and Foundations of Science, 34(3), 357-372. (https://doi.org/10.1387/theoria.19070).

Received: 27 January, 2019; Final version: 15 February, 2019.

ISSN 0495-4548 - eISSN 2171-679X / (c) 2019 UPV/EHU 


\section{Introduction}

I once heard Jerry Fodor give a talk in which he said that, given time constraints, he had to omit the arguments. I am in a similar position, given space limitations. This paper will therefore present an overview, with references to other work for support. ${ }^{1}$

Historically, the sciences have undergone several stages of epistemological weakening from the early varieties of foundationism associated with the Cartesian and Newtonian research programs (to take two leading examples). These weakenings were largely driven by the aim of opening up new domains for scientific exploration, areas where foundationists feared to tread. Thus, I see a trade-off between long-term epistemological security and rapid innovation into theoretically remote domains. With some exceptions, I don't think the strong forms of realism featured by many philosophers since the 1980s accurately reflect these changes in scientific practice. But insofar as they do, and insofar as philosophers' accounts may affect science policy, there is good reason to think that today's strong realism hampers scientific innovation. For the "strong realism" that I shall describe in general terms below requires a strong, one might even say neo-foundationist, epistemology.

Following a historical background sketch, I introduce "the crowbar model of method," an exceptionally simple model of method. My own model here is physicists, who sometimes employ models that are as simple as possible in order to bring out an important insight. The insight I want to suggest is that modeling practices typically fail to support strong realism, although they can support weak forms of realism, depending on context. This outcome supports the general claim of a rough correlation between liberalized methodology and rate of innovative research. I then introduce "the tools-to-theories heuristic" identified by Gerd Gigerenzer and employed by some who (wrongly) claim to get strong realism directly from useful modeling methods. Digital physics is my example. In the final section of the paper, I make a few sketchy remarks about the kinds of realism worth keeping.

Aside from worries about "deep" realism, explained below, I have no problem with intentional realism, an individual's aim to discover new entities and processes and her hope to produce true accounts of reality and that the theoretical terms refer. This is good-old-fashioned-realism. Intentional realism can be energizing and may have heuristic value, but it is the weak realism of people such as Popper or the hopeful realism of scientists who seriously hope to hit on the truth in deep theoretical contexts. By contrast, 'strong realism' is the claim that specified current theories are today known to be true, or very nearly so, and that their terms are known to refer. Strong realism generally discourages bold departures from the entrenched position, both in scientific practice and at the funding/policy level. Finally, by 'deep realism' I shall mean that the realism in which scientists genuinely understand the entities and processes that they claim to have discovered. Deep realism characterizes old-fashioned realism but goes beyond the structural realism of Worrall (1996).

1 See the references section for work in which I develop various aspects of my position: Nickles (1987; 2006; 2009a and b; 2017; 2018 a, b, and c; and forthcoming). 


\section{From foundational methods to the models revolution}

It is well known that, over time, high-level conceptions of scientific method moved away from the kinds of epistemological foundationism found in Descartes and Newton. To a significant degree, the historical changes were driven by the attempt to create new approaches, to open up new domains to investigation, as opposed to proceeding, at best, at a slow, incremental pace within an established framework. A prime example is the shift, in the decades around 1800 , from the broadly Newtonian conception of method to the method of hypothesis and the idea that science progresses by self-correction. As Larry Laudan has pointed out, one could make little headway in producing developed subtle-fluid theories within a Newtonian framework (Laudan 1981, ch. 8; Nickles 1986). This change included a shift in the conception of scientific progress, from derivation of Newtonian "true causes" from the observed phenomena to production of fallible but fruitful and testable theoretical hypotheses that permitted investigation of new, microphysical realms and other observationally remote domains.

Today's science affords a multitude of examples of the pressure for innovation that may depart from established methodology and from textbook "truths." Many physicists are excited when possible shortcomings of the Standard Model or conflicting measurements of the Hubble Constant and their methodological tools are announced, bringing prospects of new, original work. Examples can be found in most any field. For these scientists, the risky pursuit of new opportunities bests working in safe, well-established programs. In a sense it is a question of self-identity: they can identify as highly creative scientists only so long as they are actually doing highly creative work. ${ }^{2}$

The changes can be eliminative as well as additive. The near-dogma of causal determinism and much else related to intuitive understanding disappeared with quantum mechanics. And insofar as the today's most successful form of artificial intelligence takes holddeep learning algorithms applied to large databases-its enthusiasts must be prepared to give up traditional, intuitive scientific understanding. For today's machines are black boxes in terms of our understanding precisely how they produce their successful predictions and identifications (Nickles 2018b). It is conceivable that their pragmatic success may force a change in methodological standards in several domains. This would mean that the deep realism phase of science is coming to an end in these fields.

Here, in rough outline, are major turning points in the history of high-level scientific methodology. ${ }^{3}$

\section{TRADitional FoundaTIONISM}

Early modern methodologists such as Descartes and Newton were epistemological foundationists (of different sorts), who insisted that rigorous investigation must derive new theoretical truths from truths already known, supposedly without any use of figurative language.

2 For starters, have a look at the comments by major scientists in Brockman (2015).

3 I have selected several major moments but do not pretend that this list is comprehensive. For example, Chang's (2004) move from foundationism to coherentism to progressive coherentism could have been included. 
For Bacon and some early "empiricists," the starting point was a body of factual knowledge; whereas, for "rationalists" such as Descartes, the starting point was intellectual intuitions (with an admixture of empirical observation to fill in concrete detail). In both cases the passage from the foundation to new nomic or theoretical claims had to be logical in some sense. ${ }^{4}$

A) A major departure from foundationism, the method of hypothesis begins from conjecture rather than from known truth. Hence, according to foundationists, it could not be trusted. Yet, for several reasons, the method of hypothesis became the dominant general method of science after 1800 (Laudan 1981, ch. 11; Nickles 1987). To mention just two, hypotheses gave scientists extra premises from which to reason, pro tem. And since these could be highly theoretical premises, this method greatly extended the scope and depth of scientific work, especially into theoretical regions in which empirical domain knowledge was too sparse to get the foundational methods off the ground. As a result, many sciences could pass from a natural history phase to a mature theoretical phase, often one that became increasingly mathematical. I do not mean to suggest that theoretical hypotheses drove everything. Improved experimental design, instrumentation, and the social organization of research were also key to many advances.

B) The models revolution. What I am calling "the models revolution" has two sides: scientific practice itself and the science studies interpretation of that practice. In recent decades working scientists as well as the science studies scholars who follow them have come to recognize that scientists in all scientific fields employ models of many different kinds, leading some analysts to embrace the slogan that "science is modeling, all the way down."5 Although antecedents go back to Galileo and even Archimedes, the recent models revolution is a big step beyond the method of hypothesis in liberalizing general scientific methodology. How so? In almost every case of modeling, scientists know from the start that the representational models they construct are false, strictly speaking. This is a striking departure from the method of hypothesis, which holds out the hope that the hypothesis may be true, and that successful testing can sufficiently raise our confidence that this is the case. Much Bayesian confirmation theory is still based on this hypotheticalist idea.

Although early scientists did use models, in our highly fallibilistic sense of modeling practice, they did not tend to regard their finished products as models in our sense. Today's scientists have a heightened awareness of what they are often doing-constructing only approximate or simplified or idealized accounts, most of which are known in advance to be false. Today we are inclined to refer to older theories now known to be wrong as models, as in "Newton's model of the Solar System." And today, 'model' has taken on new life as a verb in many scientific fields. Modeling talk is now so pervasive that today's deep-learning machines are

4 See McMullin (1976). My historical sketch is extremely simplified. For instance, it is clear that Descartes engaged in some empirical investigation and that his "deductions" were not always rigorous in the later sense of 'logical deduction'. We also know that Newton employed the method of hypothesis in his research, while insisting that final publication be in something like axiomatic form, with the main principles somehow derived from "the phenomena" (Shapiro 1980).

5 E.g., Wimsatt (2007), although Wimsatt is a kind of realist. 
often said to form their own models, apparently implicitly, although we do not understand how or what (yet, anyway). As for philosophers of science-the science studies dimension of the models revolution-think of today's rapidly expanding literature on models and simulation as compared to that of the logical positivist era (Malaterre et al., forthcoming).

Increasingly pragmatic, interventionist, and pluralist attitudes toward scientific research have led many scientists and some philosophical commentators to allow even for the joint use of incompatible models to model different aspects of a phenomenon or system (Winsberg 2010,73). And the pragmatic realization that our research is conditioned by human interests, human goals, is a further dimension in the unavoidably anthropocentric cast of our science. In some fields, model-produced simulation increasingly replaces direct experimentation on nature.

The models revolution is a boon to scientific innovation, yet it brings out more explicitly than ever the human limitations that make the old dream of a strong-realist, intelligible, objective, representational account of reality unattainable. By 'objective' I mean a perspective-free account, one free of human individual and community-cultural "takes" on the world. The old realist dream was to continue the Copernican Revolution, in the sense of eliminating, one by one, the remaining, human perspectival respects in which our sciences fell short of a god-like comprehension of reality. We are now beginning to realize that scientific "discovery" itself, both about the universe and about human cognition, imposes a double limit on this strong realist, non-perspectival ambition. There is an ironic realist tension here: the more we learn about reality, the more readily we can see that strong, global realism is untenable! The models revolution speeds up this learning process while manifesting its realist limitations more clearly than before.

In my view, Cartwright (1983), Fine (1986), Giere (1988, 2006), Teller (2001), Batterman (2009), Stanford (2006), and others provide better accounts of scientific practice than what we might call "the Nowak-McMullin approach to modeling" (Nowak 1980, McMullin 1985), as successive de-idealization that converges on the one true account.

C) The rhetorical turn. Since the work of N. R. Hanson, Mary Hesse, Paul Feyerabend, and Thomas Kuhn from the late 1950s on, there has been increasing emphasis on the importance of modeling in the rhetorical sense-the use of analogy, metaphor, and simile in scientific thinking. For example, Kuhn (who was influenced by Hanson and Hesse) made the modeling relation the key to his epistemology: new research puzzles and their solutions are modeled on the highly successful old ones that Kuhn (1970, Postscript) termed 'exemplars', via a "perceived similarity relation" acquired in scientific education and professional experience.

" $\mathrm{x}$ is a model of $\mathrm{y}$ " expresses a rhetorical trope. Nearly every writer on scientific innovation now recognizes the crucial importance to innovation of these rhetorical tropes, quite in contrast to the early foundational literalists of the Royal Society as well as the 20th-century logical positivists, who were still fighting the old battle between logic and rhetoric.

D) Pragmatic satisficing. Consider Herbert Simon's work on bounded, ecological rationality, satisficing, and heuristics (e.g., his 1990). At each stage of research, he emphasized, it is not usually necessary (and often impossible) to find the perfect 
solution or even the perfect problem formulation. Rather, researchers should find a solution that is good enough to proceed to the next step and leave it at that, at least for the time being. In effect, this follows Peirce's advice to not block the road to inquiry. (In my judgment, Simon was one of the great pragmatic thinkers.) Simon's approach dovetails with the models revolution. As the titles of his books suggest ${ }^{6}$, Simon himself made a major contribution to the modeling revolution in several fields, including economics, artificial intelligence, and cognitive psychology. Clearly, Simon's sort of relaxation of traditional logical and mathematical standards of rationality, based on human cognitive and epistemic limitations as well as situational complexity, can accelerate research.

E) The heuristic turn. Bounded rationality necessitates the need for heuristic shortcuts, so Simon also championed the importance of heuristic search, another departure from traditional logical requirements. The old view that heuristics (sometimes embedded in analogy or metaphor) are temporary shortcuts or scaffoldings that will eventually give way to fully constructed procedures is giving way to the view that heuristic thinking lies at the core of innovative research. If rapid innovation is what we want, heuristic fertility judgments are usually more productive than absolute truth claims. It is worth noting that the liberalizing methodological turns being described here were themselves heuristically motivated, in the sense that method B is considered more likely to be fruitful than method A.

F) Coupling. A further speed-up has been achieved by rejecting the old view, retained by the logical positivists, that data, theory, instrumentation, research design, aims, and criteria of evaluation must be kept strictly independent of one another. For if data were theory-laden, for example, empirical tests might become circular. A self-reinforcing dogmatism can set in. Kuhn's view of theory-laden data and paradigm-relative standards was savaged by Israel Scheffler (1967) in Science and Subjectivity as a radical departure from scientific objectivity. For many, Kuhn's incommensurability of competing paradigms is the horror story that results when virtually all of these factors are coupled. ${ }^{7}$ By contrast, Kuhn saw this coupling as a key to understanding rapid scientific progress.

Surely some degree of coupling has been crucial to rapid progress. As we now know, there is no such thing as a general, neutral scientific method that has much heuristic or problem-solving power. Scientists themselves discovered this early in the game, and artificial intelligence researchers quickly discovered that completely general, domain- and problem-neutral heuristics were of limited value. According to Allen Newell (1969, 368f):

Evidently there is an inverse relationship between the generality of a method and its power. Each added condition in the problem statement is one more item that can be exploited in finding the solution, hence in increasing the power.

6 Among these titles are Models of Bounded Rationality, Models of Discovery, Models of Man, Models of Thought, and Models of My Life.

7 See Laudan's (1984, ch. 4) critique of Kuhn's holism. 
The very idea of "the (general) scientific method" was on its way out. For example, we now recognize that substantive theoretical content is often built into the methods and the apparatus themselves (both hardware and software). Modeling practices especially blur the distinction between substantive content and methodological tools. Theoretical advances can create new methodologies. As Peirce $(1877, \$ 1)$ insightfully remarked, "each chief step in science has been a lesson in logic." To think that method comes first is to adopt a mindfirst, creationist conception of scientific innovation (Dennett 1995, Nickles 2009).

This coupling compromise, as we might call it, is thus another departure from the puritanical dictates of traditional methodology and, as such, should further undercut our belief that our most mature current theories and models are true. Coupled factors can produce an interesting, nonlinear dynamics, an extreme version being early Kuhn's account of mature scientific practice as producing an unending series of scientific revolutions.

\section{Summary}

Logic and history of science both suggest that there is a rough tradeoff between rate of innovative research and strong realism. Hypotheticalism, the modeling revolution, the rhetorical turn, pragmatic satisficing and pluralism, the heuristic turn, and methodological coupling all depart from the austere dictates of early scientific epistemology and methodology. Yet, as a matter of historical fact, these relaxations did not destroy science. On the contrary, they accelerated scientific progress, albeit with fits and starts along the way. They produced powerful new tools for tackling the unknown, for moving the research frontier. I claim that the epistemological risk they introduce with regard to major truth-attainment weakens the case for strong scientific realism. Progressive sciences nearly always undermine their previous major results, ${ }^{8}$ yet it was precisely those untrue claims that facilitated the progress.

\section{The crowbar model of a methodological tool and the crowbar compromise}

Methods are humanly-designed tools for inquiry, tools for doing things that can be tested for effectiveness in diverse domains. One can model methods as tools. One familiar type of model is abstract, such as Bacon's or Descartes' series of content-free steps, or the five-step method of hypothesis that we all learned in grade school. Here I want to introduce a different sort of model, crude but suggestive, in accord with the physicists' practice of keeping models as simple as possible in order to bring out a useful insight. In my classes I have long introduced the crowbar or prybar as a tool that serves as a simple model of any tool, including scientific methods. A crowbar (some quite large, others small) is a lever with a handle at one end and an (often notched) wedge at the other, generally curved end, somewhat reminiscent of a crow's foot. The French is pied de biche, doe's foot; the Italian piede di porco, pig's foot, or else palanchino; the Spanish and Catalan being palanca. In British empire English it is a "jimmy" or "jemmy." The German is Stemmeisen or Brecheisen."

8 In science as in politics, revolutions (and major changes more generally) typically devour their parents.

9 Thanks to the Tekton and Amazon companies for the images. 

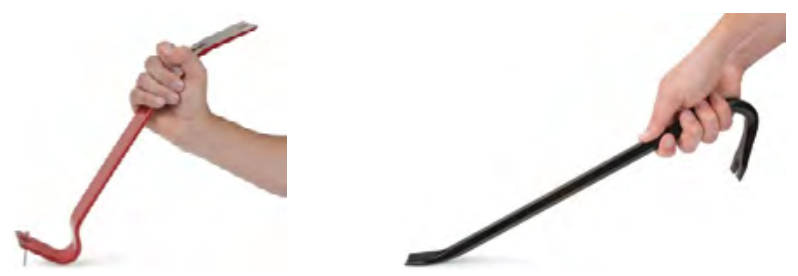

To be a useful tool, the crowbar must sufficiently fit the world at one end and the human hand at the other. ${ }^{10}$ In a world of tomato soup, crowbars are useless. They are also useless to jellyfish. The point here is that, in order to be useful, the crowbar has to incorporate or embody "knowledge" of the domain of application on one end and "knowledge" of human capabilities on the other. As we might say, the one end has to embody a degree of realism about the world and the other end a degree of realism about user capabilities.

Neither of the two elements of realism just mentioned are precise enough to count as strong realism (see below), and they are in tension with one another. Our most mature physical sciences have shown how weird and complex reality must be (given that all simple or intuitive accounts have failed), while cognitive and other sciences (e.g., physics again) are revealing our cognitive limits. Therefore, it is quite possible that we are incapable of handling some domains in their full complexity.

Thus human science runs up against two kinds of limits, both of them limits discovered by science itself, limits on what any nomically possible method can accomplish at the world "end" as well as what any specific method, technique, or apparatus can accomplish (cf. Giere 2006), and limits that require the human "end" to fit our biologically and culturally evolved cognitive capacities. The instrumental extension of human capacities only postpones the point, for, ultimately, we must be able to use our instruments skillfully.

The two-fold investigative limits are embodied in the two "ends" of even our best tools.

Accordingly, our tools are compromises. We should not think of them as providing us with direct access to unvarnished nature. ${ }^{11}$ Insofar as they are usable by us, they must provide a human take on reality. Call this the crowbar compromise. Simply ignoring the compromise and projecting the human take onto the natural world is the crowbar fallacy. ${ }^{12}$

To mention one range of cases, our efforts to understand the world are compromised by what we are able to make intelligible. ${ }^{13}$ Newtonian action-at-a-distance was already a

10 Simon $(1990,7)$ made a somewhat similar point using scissors as his metaphor. "Human rational behavior ... is shaped by a scissors whose two blades are the structure of task environments and the computational capabilities of the actor."

11 This point overlaps old ones about observation as theory laden.

12 Here I am very much in tune with Giere's perspectivism, although I doubt that it should be considered a form of realism. Giere writes: "[T] he strongest claim that can justifiably be made has the general form something like: Given the assumed observational and theoretical perspectives, [model] $\mathrm{M}$ exhibits a good fit to the subject matter of interest. There is no basis for going further to a supposed more objective, nonrelativized claim that this is how the world is, period" $(2006,92)$.

13 Lack of intelligibility or sense of understanding need not undercut usability, as the examples below indicate, but it does undercut the plausibility of old-fashioned scientific realism. For a somewhat different view, see (Trout 2002). 
case in point during the so-called Scientific Revolution. Newton's equations worked wonderfully to predict many things quite precisely, but no one could (or can, to this day) understand or imagine what sort of mechanism could produce instantaneous action-at-a-distance. Thus, it was impossible to justify deep realism about Newtonian mechanics. Today, we think first of quantum mechanics as a further obstacle to transparent intelligibility. Surely, one reason for the models revolution is that several of our sciences, including our most mature ones, are now becoming so complex that we cannot deal with them directly. Nature itself, in addition to our own limitations, forces us to model. Both ends of the crowbar exert pressure toward modeling.

Four hundred years of modern science is much too short a time to claim that some of our sciences are sufficiently mature to support claims of strong realism (Nickles, 2018a). Do we seriously think that we are at the end of major progress in theoretically deep areas, that scientists a thousand years in the future will be taking our results as (nearly) final? In my view, the crowbar compromise (in which the coupling compromise is implicit), and a pragmatic conception of the goals of science as conditioned by human interests, imply that there will always be a strain of anthropocentrism in our science. Thus, I must agree with Ronald Giere's perspectivism (2006) (modulo footnote 13) and disagree with Paul Humphreys when he writes, in the preface to Extending Ourselves (2004):

The influence of computational methods on science today is ... striking. ... [M] any parts of science have, as a result, entered a distinctively different phase of their development. In this and in other areas, human abilities are no longer the ultimate criteria of epistemic success. Science, in extending its reach far beyond the limits of human abilities, has rendered anthropocentrism anachronistic.

Yet it is still we ourselves that we are extending. To adapt a famous remark of William James (1907, Lecture II): "The trail of the human serpent is still over everything." Meanwhile, the intelligent beings of the planet Zork will have a Zorkocentric conception of the universe.

Nonetheless, there is an implicit realism in my crowbar model. For the crowbar to work well (as we know that it sometimes does), a part of the world must be "engage-able" at one end, just as the other end is humanly graspable. If the crowbar works anywhere at all for us, this already tells us that that part of the world is not tomato soup-and that we are not jellyfish!

\section{The tools-to-theories (TTT) heuristic as an attempt to evade the crowbar compromise}

Gigerenzer (1991) discovered in cognitive psychological practice and elsewhere what he calls "the tools-to-theories heuristic." Let's call it TTT for short. This is a remarkable theory-generation strategy, because it generates an elaborate theory in one step, by, in effect, redescribing or theoretically projecting method as an ontic mechanism. ${ }^{14}$

${ }^{14}$ See also Gigerenzer and Murray (1987), Gigerenzer and Goldstein (1996), and Gigerenzer and Sturm (2007). 
One of Gigerenzer's motivations is to overcome the invidious, traditional epistemological distinction between context of discovery and context of justification. He sees the TTT heuristic as a better account of actual theory generation practice than either the data-driven accounts inspired originally by Bacon or the romantic, theory-driven accounts found in Karl Popper, to mention two extremes. For one thing, TTT is more domain specific. For another, it is a practice-centered rather than a theory-centered account of much research. Third, it couples discovery and justification in a complex way, one that calls attention to the historical path-dependence of the TTT heuristic and thus possible weaknesses as well as strengths.

What is the tools-to-theories (TTT) heuristic? According to Gigerenzer and Sturm (2007, 309, their emphasis):

The tools-to-theories heuristic is twofold:

1. Generation of new theories: The tools a scientist uses can suggest new metaphors, leading to new theoretical concepts and principles.

2. Acceptance of new theories within scientific communities: The new theoretical concepts and assumptions are more likely to be accepted by the scientific community if the members of the community are also users of the new tools.

Consider Neyman-Pearson statistics, originally developed as a methodological tool by scientific specialists for data analysis and hypothesis evaluation. Some cognitive psychologists found the methodology useful, and they eventually projected it onto the ordinary human mind as the subconscious mechanism for intuitive human decision making. In short, they claimed that ordinary humans are intuitive statisticians. And, similarly, for Fisher's ANOVA (analysis of variance) methods for reasoning about causality. During the cognitive revolution of the 1960s, the computer as a research tool became the preferred model of the mind itself. We are intuitive computing machines. A fourth example is Richard Gregory's Helmholtz-inspired account of perception as unconscious inference: the perceiving mind generates and tests zillions of hypotheses per second in much the way the scientific community generates and tests hypotheses.

Nickles (2018c) asks whether the TTT heuristic applies to explicitly non-psychological cases, especially today's information-theoretic biology and digital physics. Some biologists with a gene-centric emphasis regard biological reality itself as just information being transformed in various ways. Several physicists adopt J. A. Wheeler's (1982) motto of “'it' from 'bit"' in regarding reality itself as informational bit strings transformed by the universe conceived as a quantum computer.

There is no question that informational and computational approaches can be revealing. Modeling genes as informational is instructive, and digital physics has become a specialty area of its own. Nonetheless, my view is that simply elevating useful tools of methodological analysis to the representational status of the real processes of target systems is usually unwarranted. Digital physicists, for instance, are often cavalier in their statements, sliding too quickly between talk of simulation and talk of reality. Sometimes they seem driven to out-radicalize one another. Is TTT is somewhat more plausible when applied to human subjects than to developmental biology or to the physical universe, since the scientists themselves are, of course, also human?

As noted above, the TTT heuristic strongly couples discovery and justification. The scientific practices that employ the research tools are well established before the ontic pro- 
jection is made. The theoretical concepts are therefore already anchored in familiar practice. Thus researchers find it relatively easy to accept the theory as correct. Too easy! As Gigerenzer and company point out, there is danger here. Insofar as the theory is a direct projection of the practice, there is a vicious circularity, one that can lead to exclusion of data generated by other practices and thus foster dogmatic entrenchment. Independent confirmation is badly needed. Of course there is mutual support of theory and practice in the pure TTT case, since one is just the ontic projection of the other. In at least some cases, TTT pretends to turn a statistical-correlational analysis into a postulatory theory that purports to explain the very phenomena that the statistical analysis produced from the data. It is tempting in such cases to rhetorically construct a revisionary history of the research path, forcing it into the traditional hypothetico-deductive model, as if the research practice had actually been a rigorous test of the theory.

Another worry is that the projections are metaphorical. It is as if our visual system contained a community of scientist-homunculi rapidly formulating and testing incoming visual data. After all, both metaphors and heuristics have their limits. Gigerenzer and Sturm observe that the scientists in question too quickly forget the metaphorical path-dependence of their work, that today's technology-based metaphors will likely be replaced as science and technology continue to advance. Gigerenzer's work updates the old theme that every era attempts to solve its biggest puzzles in terms of the most advanced technological practices of the day. If history is any guide, our current technological metaphors will not be the last.

Nonetheless, Gigerenzer does think there is something positive in the TTT mode of theory generation, although Gigerenzer and Sturm (2007) are later more critical. First, TTT is an important way of generating theory candidates. TTT works to establish "proof of concept," and that is interesting in itself. Second, there is a positive side to the worry about the metaphorical origins of the ontic projection. Calling attention to this and to the implicit use of the TTT heuristic can lead scientists to reflect critically on their work, asking whether or not the metaphor has become a scientifically legitimated, dead metaphor. Even in successful cases, the metaphorical, heuristic origins can point to possible weaknesses in the theory.

A different way of regarding the TTT heuristic is as a desperate way of trying to save scientific realism in complex domains. Insofar as the TTT leap is meant literally (rather than providing a just-so, metaphorical model), it tames the frontier by simply identifying order of knowing with order of being, to use Aristotelian vocabulary. This is essentially the mistake made by the crowbar fallacy-confusing the two "ends" of our research tools. That the human end works well does not mean that the other end does. Such a move reifies methodological procedures, surely an unreliable way of defending a realist view of science. The TTT move simply sweeps problems of realism, representation, and correspondence truth under the rug. (Notice that 'representation', like 'model' is ambiguous precisely in the way the crowbar fallacy warns: representation as a perhaps cognitively useful way of treating $\mathrm{y}$ is different from representation as a literally true way of describing y.

Are humans and nonhuman animals really subconsciously computing their behavioral responses in this manner? Compare the use of rational decision theory and game theory to characterize the behaviors (e.g., the caching behaviors or mate choice) of many species that have been studied. This can be taken as an "as-if" description of the behavioral competence 
of these creatures rather than as a literal explanation of how in fact they do it. Thousands of generations of evolution have taught the animal or plants to act as if they are applying these methods, but how they are actually accomplishing this in terms of their concrete embodiment in relation to their environmental niches is surely a separate question. The question is a substantial one that requires much additional investigation. It often seems to be a matter of heuristic shortcuts, processes triggered by detected ambient factors, as when the female responds to the peculiar "dance" of the male sage grouse or the number of "eyes" in the tail fan of the peacock.

The TTT heuristic and the crowbar compromise provide another way to raise two questions central to philosophy of science. (2) Given that many scientific concepts, models, and theories have a rhetorical origin, say a metaphorical one, what does it take for a "live" metaphor to become scientifically justified and thus a dead metaphor? (2) Given that some TTT-like move is involved in much theory formation, what does it take to make ontic projection scientifically plausible as a serious realist claim?

\section{Scientific realism and progress}

As everyone knows, there has been a decades-long debate over whether scientific realism is the most plausible position to defend, a complete nonstarter, or something in between. Meanwhile, a proliferation of realisms and non- and anti-realisms have emerged. Some say that the debate has reached an impasse, but it seems to me that the models revolution and the other departures from traditional methodology, which was strongly realist, weaken today's claims for strong realism, especially in those areas where the natural or social processes are so esoteric, so complex, or so overwhelmingly detailed that they are beyond anything like complete literal understanding, at present at least. The very same methodological devices that have sped up research reduce our confidence that what we are discovering are deep truths of the strong realist variety. We now appreciate that rapid progress can be made on the basis of false theories or models as well as faulty understanding of scientific instruments such as the microscope (Hacking 1983, ch. 8). In fact, we know that rapid progress can be made this way, because it has been made this way. Strong realists sometimes claim that it is impossible to understand scientific progress without a key role for Big Truth, but, given the usual absence of the latter in scientific practice, the burden fallss upon them (as well) to explain how so much progress is possible without it.

A realist critic of my position will likely object that I cannot say both that the hypotheticalist and modeling revolutions have sped up scientific progress and that they undercut realism. For what could scientific progress be other than an approach to the final "metaphysical" truth about the world? And how is it possible that scientific advances undermine realism rather than fortifying it? Given the weight that I have placed on progress, I must (all-too-briefly here) sketch my answer. Again, my answer features innovation and heuristic fertility rather than (unknowable) distance from the (unknowable) truth.

First, saying what constitutes scientific progress is a problem for everyone, realists and nonrealists alike (Chang 2004, 2012). Contrary to what some realists imply, it is not a problem only for critics of realism. 
Second, minimal (small-scale or "retail”) realism is enough to undercut stronger forms of realism. There are many forms of minimal realism: local realism, structural realism, instrumental realism, etc. Popper (1962, ch. 3) was a strong intentional realist but a very weak epistemological realist, since he held that we can be pretty sure that a given general theory is wrong but never that one is right. This "negative realism" or "falsificationist realism" (what the universe is not) is most of what I need to make my point that we now understand that many natural processes are too complex or too weird for full, literal human intelligibility. There is an element of truth in structuralism for much the same reason: there are cases in which we can use equations to make extraordinarily accurate predictions, without our really understanding how to interpret them in terms of basic-level processes (Worrall 1996). In this respect, several of our most mature sciences give us only a limited "metaphysical" account of the world. Most of our explicit knowledge about the universe is structural in nature: we have a good idea how electrons behave in terms of mathematical equations (for example), but do we really know what they are-and do the intelligent Zorkians postulate electrons and protons at all? The TTT mode of innovation can be regarded as a desperate attempt to save strong realism, yet it is obviously the imposition on the world of our latest human metaphorical "take."

A more positive third point is that we can regard the products of scientific work as more akin to technological products than as near-final representational truths. Here the question is not whether a tool is true but, instead, whether it suffices for the job we want done. Saying that the Standard Model approaches the final perfection of physical theory is rather like saying that today's Internet approaches the highest pinnacle of information technology. Fourth, ditto for research processes. "Basic" scientific breakthroughs are similar to technological breakthroughs in opening up fertile new possibilities, prior to producing finished products. We are able to conceive and do things not possible before. Chang's $(2004,2012)$ work on measurement applies to both of these points and can be extended to conceptual tools.

Fifth, science makes rapid progress in the realm of subarticulate knowledge-how. Good researchers are expert tool users and inventers of new tools. They know how to conduct research and to solve problems that a non-expert who knows all the right equations cannot. Here I am attracted by Davis Baird's (2004) work on "thing knowledge" and by Lorenzo Magnani's (2004) on "manipulative induction." The crowbar model of research tools already suggests that, when we can use the tool successfully, there is knowledge incorporated in the tool, or at least in the combination of the tool and the human expert who uses it. This is instrumental realism in the sense that we can ask what the world must be like (or at least not like) and what human cognition must be like in order for specific tools to work so well in a given context, and the answer places constraints on what sort of world that could be. Here again I join Gigerenzer and the ABC Group (1999) in appreciating the influence of Herbert Simon's ecological approach. Gigerenzer's group aims to provide an account of psychological mechanisms, ones that exhibit as much bio-cognitive economy as possible, i.e., mechanisms built around heuristics: "Heuristics, at their core, are models of the cognitive process" (Schooler and Hertwig 2011, 156). And, following Simon's ecological approach, successfully evolved cognitive processes themselves (and their heuristics) model the environmental niches in which the organisms find themselves. 
A critic may also point out that making risky research decisions does not make one a nonrealist. A recent example is Craig Venter's recent work in genomics. He took enormous risks but succeeded in establishing several, apparently correct genomic sequences (Venter 2007). I agree with the objection, but I am not equating risky decisions with nonrealist ones. Again, I am only a local realist / nonrealist, not a global one. I also agree that many modelers (although far from all) are realists in the sense that they hold that, while present models are limited, a long series of improving models will eventually arrive at the true model (the Nowak-McMullin view). However, even here, much of what I want to claim holds in the interim: the modeling pro tem does not claim to arrive at the truth, let alone meeting the standards of strong as opposed to intentional realism, yet it is what makes possible, or constitutes, the progress. Nor is there a prior guarantee that it ever will achieve final truth. The 'tem' of 'pro tempore' can be a long time! This sort of realist retains a relaxed conception of scientific work compared with more foundationist strictures, one that need not hamper innovative research.

I will end on this fairly irenic point, but there is much work left to do.

\section{REFERENCES}

Baird, Davis. 2004. Thing knowledge. Berkeley: Univ. of California Press.

Batterman, Robert. 2009. Idealization and modelling. Synthese 169/3: 427-446.

Brockman, John, ed. 2015. This idea must die: Scientific theories that are blocking progress. New York: Harper. Cartwright, Nancy. 1983. How the laws of physics lie. Oxford: Oxford Univ. Press.

Chang, Hasok. 2004. Inventing temperature: Measurement and scientific progress. Oxford: Oxford University Press.

Chang, Hasok. 2012. Is water $\mathrm{H}_{2} \mathrm{O}$ ? Evidence, realism and pluralism. Dordrecht: Springer.

Dennett, Daniel. 1995. Darwin's dangerous idea. New York: Simon \& Schuster.

Fine, Arthur. 1986, The shaky game: Einstein, realism, and the quantum theory. Chicago: Universtiy of Chicago Press.

Giere, Ronald. 1988. Explaining science: A cognitive approach. Chicago: University of Chicago Press.

Giere, Ronald. 2006. Scientific perspectivism. Chicago: Univ. of Chicago Press.

Gigerenzer, Gerd. 1991. From tools to theories: A heuristic of discovery in cognitive psychology. Psychological Review 98: 254-267.

Gigerenzer, Gerd. 1992. Discovery in cognitive psychology: New tools inspire new theories. Science in Context 5: 329-350.

Gigerenzer, Gerd and David J. Murray. 1987. Cognition as intuitive statistics. Hillsdale, NJ: Lawrence Erlbaum.

Gigerenzer, Gerd and Daniel Goldstein. 1996. Mind as computer: Birth of a metaphor. Creativity Research Journal 9/2\&3: 131-144.

Gigerenzer, Gerd, Peter Todd, and the ABC Research Group. 1999. Simple heuristics that make us smart. Oxford: Oxford University Press.

Gigerenzer, Gerd and Thomas Sturm. 2007. Tools = Theories = Data? On some circular dynamics in cognitive science. In Mitchell Ash and Thomas Sturm, eds., Psychology's territories: Historical and contemporary perspectives from different disciplines, pp. 305-342. Mahwah, NJ: Lawrence Erlbaum Associates.

Hacking, Ian. 1983. Representing and intervening. Cambridge: Cambridge University Press.

Hesse, Mary. 1963. Models and analogies in science. London: Sheed and Ward. 
Humphreys, Paul. 2004. Extending ourselves: Computational science, empiricism, and scientific method. Oxford: Oxford University Press.

James, William. 1907. Pragmatism. New York: Longmans.

Kuhn, Thomas S. 1970. The structure of scientific revolutions. 2nd ed. with Postscript-1969. Chicago: University of Chicago Press.

Laudan, Larry. 1981. Science and hypothesis. Dordrecht: Reidel.

Laudan, Larry. 1984. Science and Values. Berkeley: University of California Press.

Magnani, Lorenzo. 2004. Reasoning through doing: Epistemic mediators in scientific discovery. Journal of Applied Logic 2: 439-450.

Malaterre, Christophe, Jean-François Chartier, and Davide Pulizzotto. Forthcoming. What is this thing called Philosophy of Science? A computational topic modeling perspective 1934-2015. Hopos.

McMullin, Ernan. 1976. The fertility of theory and the unit for appraisal in science. In John Worrall, Robert S. Cohen, Paul Feyerabend, and Marx Wartofsky, eds. Essays in memory of Imre Lakatos, pp. 395-432. Dordrecht: Reidel.

McMullin, Ernan. 1985. Galilean idealization. Studies in History and Philosophy of Science 16: 247-73.

Newell, Allen. 1969. Heuristic Programming: Ill-structured problems. In Julius Aronofsky, ed. Progress in operations research III, ch. 10. New York: Wiley.

Nickles, Thomas. 1987. From natural philosophy to metaphilosophy of science. In Robert Kargon and Peter Achinstein, eds., Kelvin's 'Baltimore lectures' and modern theoretical physics, pp. 507-541. Cambridge, MA: MIT Press.

Nickles, Thomas. 2006. Heuristic appraisal: Context of discovery or justification? In Jutta Schickore and Friedrich Steinle, eds. Revisiting discovery and justification, pp. 159-182. Dordrecht: Springer.

Nickles, Thomas. 2009a. The strange story of scientific method. In Joke Meheus and Thomas Nickles, eds. Models of discovery and creativity, pp. 167-207. Dordrecht: Springer.

Nickles, Thomas. 2009b. Life at the frontier: The relevance of heuristic appraisal to policy. Axiomathes 19: 441-464.

Nickles, Thomas. 2017. Cognitive illusions and nonrealism: Objections and replies. In Evandro Agazzi and Mario Alai, eds. Varieties of scientific realism, pp. 151-163. Vienna: Springer.

Nickles, Thomas. 2018a. Is scientific realism a form of scientism? In Maarten Boudry and Massimo Pigliucci, eds. Science unlimited? The challenges of scientism, pp. 145-163. Chicago: University of Chicago Press.

Nickles, Thomas. 2018b. Alien reasoning: Is a major change in scientific research underway? Topoi. Published online 20 March. https://doi-org.unr.idm.oclc.org/10.1007/s11245-018-9557-1

Nickles, Thomas. 2018c. TTT: A fast heuristic to new theories and models? In David Danks and Emiliano Ippoliti, eds. Building theories: Hypotheses and heuristics in science, pp. 169-189. Vienna: Springer.

Nickles, Thomas. Forthcoming. Cognitive illusions confront scientific realism. In Wenceslao J. González, ed. New approaches to scientific realism.

Nowak, Leszek. 1980. The structure of idealization. Dordrecht: Reidel.

Peirce, C. S. 1877. The fixation of belief. Widely reprinted.

Popper, Karl R. 1962. Conjectures and refutations. New York: Basic Books.

Scheffler, Israel. 1967. Science and subjectivity. Indianapolis: Bobbs-Merrill.

Schooler, Lael and Ralph Hertwig. 2011. How forgetting aids heuristic inference. In Gerd Gigerenzer, Ralph Hertwig, and Thorsten Pachur, eds. Heuristics: The foundations of adaptive behavior, pp. 82-107. Oxford: Oxford University Press.

Shapiro, Alan, 1980, The evolving structure of Newton's theory of white light and color. Isis 71: 211-235.

Simon, Herbert A. 1990. Invariants of human behavior. Annual Review of Psychology 41: 1-19.

Stanford, P. Kyle. 2006, Exceeding our grasp: Science, history, and the problem of unconceived alternatives. New York: Oxford University Press.

Teller, Paul. 2001. Twilight of the perfect model model. Erkenntnis 55/3: 393-415.

Trout, J. D. 2002. Scientific explanation and the sense of understanding. Philosophy of Science 69/2: 212-233. 
Venter, J. Craig. 2007. A life decoded: My genome, my life. New York: Penguin.

Wheeler, John Archibald. 1982. The Computer and the universe. International Journal of Theoretical Physics 21/ 6-7: 557-572.

Wimsatt, William. 2007. Re-engineering philosophy for limited beings: Piecewise approximations to reality. Cambridge, MA: Harvard Univ. Press.

Winsberg, Eric. 2010. Science in the age of computer simulation. Chicago: Univ. of Chicago Press.

Worrall, John. 1996. Structural realism: The best of both worlds. In David Papineau, ed., The Philosophy of Science. Oxford: Oxford Univ. Press.

Tномаs Nickles is Foundation Professor of Philosophy Emeritus, University of Nevada, Reno, USA, and a fellow of the American Association for the Advancement of Science. He has a life-long interest in "scientific discovery" issues, including heuristics, problem solving, and factors influencing rate of progress. He favors historical approaches to the issues.

Address: Dept. of Philosophy (0102). University of Nevada, Reno (Reno, NV 89557), USA. Email: nickles@unr.edu 